\title{
C-30 AN ANALYTICAL APPROACH FOR MODELLING THE THREE-DIMENSIONAL DISTRIBUTION OF CATACLASTIC ROCKS
}

F. SALVINI', A. BILLI', F. STORTI' and R. GAMBINI ${ }^{2}$

${ }^{1}$ Rome University, Dipartimento di Scienze Geologiche, L.go S. L. Murialdo 1, 00146 Rome, Italy 'Enterprise Oil Italiana

\begin{abstract}
Spatial distribution and three-dimensional location of cataclastic rocks within fault zones deeply influence their rheology and permeability properties. Despite their importance in hydrocarbon research and development, location and triggering factors of cataclasite formation are poorly understood. We present results of numerical models specifically developed to investigate the spatial distribution of cataclasis forming and enhancing factors along fault surfaces. Seven main factors controlling cataclasis have been identified: uniaxial stress, residual stress, stress drop, fracture interference' block rotation, pre-existing fractures and rock anisotropy. Their weighted combination with physical boundary conditions such as the fault surface geometry, the fault kinematics, the vertical load, the regional stress, the kinematic stress, the rock rheology and the rock strength, provides the cataclasite generation function. This function is a scalar value proportional to the relative probability of formation of cataclastic rocks along faults. Comparison with field data from seven test sites in the Southern Apennines demonstrated that the modelling successfully predicts the location of cataclastic bands along faults with different geometry and kinematics.
\end{abstract} occur. 